\title{
ENSINO DO DIREITO ROMANO NO BRASIL E NA AMÉRICA LATINA EM GERAL ${ }^{1}$
}

\author{
Álvaro Villaça Azevedo \\ Professor Titular do Departamento de Direito Civil \\ Ex-diretor da Faculdade de Direito da Universidade de \\ São Paulo e da Faculdade Mackenzie
}

\begin{abstract}
Resumo:
A importância do ensino do Direito Romano quanto ao seu sistema jurídico latino-americano, a sua aplicação no Brasil e a necessidade de pesquisas na área são alguns dos itens abordados pelo autor neste trabalho.
\end{abstract}

\begin{abstract}
:
The importance of Roman Right teaching with relationship to its latin-american juridical system, its application in Brazil and the need of researches at the area are some of the items approached by the author in this work.
\end{abstract}

Unitermos: Direito Romano; ensino no Brasil e na América-Latina.

\section{Sumário:}

I Importância do ensino do Direito Romano. II Sistema jurídico latino-americano e o Direito Romano. III Ensino do Direito Romano no Brasil. IV Necessidade de pesquisa sobre dados do ensino do Direito Romano na América Latina.

I Importância do ensino do Direito Romano

O Direito Romano privado, que objetiva as relações das pessoas, vivendo em sociedade, impôs-se aos sistemas jurídicos dos povos, principalmente por seu conteúdo ético, lógico e prático, na solução dos problemas cotidianos.

1. Manifestaçāo enviada ao "X Congreso Latinoamericano de Derecho Romano" realizado de 12 a 15 de agosto de 1996, em Lima, Peru, alualizada em alguns pontos. 
A essência lógica do sistema romano passou a integrar as normas das nações, a ponto de criar-se, em algumas delas, um sistema próprio, de feição romanística.

Podemos dizer, desse modo, que os países da América Latina podem enquadrar-se nesse sistema romanístico, que se destaca ao lado dos sistemas orientais e do da Common Law.

Mesmo no sistema da Common Law, presente na Grã-Bretanha e nos EUA, em que a conduta se rege por um conjunto de normas consuetudinárias, que se vão tornando obrigatórias pelas decisões dos tribunais, não foge ele à influência romana, em face dos costumes que foram assimilados por essas civilizações angloamericanas.

Todavia, é preciso resistir à improvisação das decisões judiciais desapegadas do sistema romano escrito, porque acarretam a indecisão e a insegurança sociais, em verdadeiro desequilíbrio dos princípios axiológicos jurídicos.

É preciso que exista um sistema jurídico codificado, como diretriz básica do comportamento da sociedade, para que esta possa saber o que deve ser feito e o que deve ser evitado. Assim, estarão assegurados os valores fundamentais do Direito, com a ordem e a segurança esperadas.

No próprio sistema da Common Law, surgiram as Rules of Equity, para atenuar os rigores do Direito Comum e do Estatutário (Statute Law).

Entretanto, o costume não pode ser aplicado pelo Poder Judiciário, com uma visão direta dos fatos, sem o devido amadurecimento e sem o respaldo de um sistema codificado que represente uma tradição sólida, lógica e segura, como a do Direito Romano, na solução dos problemas que afligem a sociedade.

Bem ressalta Pierangelo Catalano (Direito Romano Atual, Sistemas Jurídicos e Direito Latino-Americano, in Revista de Direito Civil, Imobiliário, Agrário e Empresarial, Ed. Revista dos Tribunais, São Paulo, abril/junho de 1988, v. 44 , pp. 7 a 27 especialmente pp. 15 a 17) que "a luta entre o Direito Romano atual da América Latina e o Direito anglo-americano deve ser considerada em um quadro geral, que é certamente iluminado por aquilo que, já na primeira metade de nosso século, escrevia o maior expoente da sociological jurisprudence, Roscoe Pound, professor da Universidade de Harvard. Ele individualizou a força da Common Law em relação ao seu rival modern Roman Law no 'modo de tratar as controvérsias concretas', isto é, no poder de criar o Direito 'através de decisões das 
causas': uma força que explica a slow but persistent invasion of the common law. Tal invasão tem encontrado infelizmente aliados, mais ou menos conscientes, também entre os romanistas. Um outro mérito histórico de Pound é de ter visto a característica de conteúdo do Direito anglo-americano (evocando também as vicissitudes do Direito germânico) naquilo que ele chamou ultraindividualism (ou extreme individualism). Ora, uma vez esclarecido (como fez Francesco De Martino na sua polêmica contra os nacional-socialistas) que o Direito Romano não é de modo algum individualista, compreende-se a substância do confronto entre o sistema jurídico latino-americano e o anglo-americano.

Informam Alexandre Correia e Gaetano Sciascia (Manual de Direito Romano, Ed. Sedegra, Rio de Janeiro, $5^{\mathrm{a}}$ ed., p. 14) que, no final do século XVIII e no século XIX, se manifestou nos "vários países, regidos pelo Direito Romano Justinianeu, uma forte corrente para codificar-Ihes as normas, segundo o princípio de auto-suficiência próprio da legislação bizantina. Organizaram-se assim as codificações modernas, nas quais o Direito Romano, quer o anterior a Justiniano, quer o posterior, não tem valor de lei por força própria, mas tão-somente enquanto acolhido e reconhecido pelas normas dos códigos e pelos princípios gerais de direito deles resultantes." E completam, relacionando, em ordem cronológica, as codificações surgidas na América Latina: Haiti, em 1826; Bolívia, em 1831; S. Domingos, em 1845; Peru, em 1852; Chile, em 1857; Equador, em 1861; Venezuela, em 1863; Nicarágua, em 1867; Uruguai, em 1868; Argentina, em 1871; México, em 1871; Colômbia, em 1873; Guatemala, em 1877; Salvador, em 1880; Costa-Rica, em 1887; Paraguai, em 1889; Cuba, em 1889; Honduras, em 1891; e Panamá, em 1917.

Com essa tendência natural dos países latino-americanos solidificarem seus sistemas legislativos, com fundamento no Direito Romano, cresce de vulto e de importância a necessidade de que seja esse Direito ensinado em suas faculdades, ao lado das disciplinas fundamentais da Ciência Jurídica.

II - Sistema Jurídico Latino-Americano e o Direito Romano

É possivel falar-se em sistema jurídico latino-americano, pois ele se forma sobre a base segura do Direito Romano, que está presente nos projetos de codificação do Direito na América Latina.

Sem dúvida alguma, podemos dizer que, no Brasil, sobressaem, nesse trabalho de pré-legislação, os juristas Augusto Teixeira de Freitas e Clóvis 
Bevilaqua. Citem-se, no mesmo sentido, as contribuições de Andrés Bello, no Chile, e de Damácio Vélez Sarsfield, na Argentina.

Entretanto, esse sistema jurídico latino-americano não é homogêneo, pois o Direito Romano, que a ele se incorporou, passou, antes disso, por vários países, sofrendo variadas influências.

Comenta o saudoso Sílvio Meira (IX Congresso Latino-Americano de Direito Jalapa México, Romanismo e indigenismo dos juristas latino-americanos, in Revista de Informação Legislativa, Brasília, n. 127 Ed. Senado Federal, Brasília, 1995, pp. 259 a 266, especialmente pp. 259 e 261; e O jurisconsulto brasileiro Augusto Teixeira de Freitas e a recepção do Direito Romano na América Latina no século XIX, in Revista do Instituto dos Advogados Brasileiros, Rio de Janeiro, n. 55 , $19782^{\circ}$ semestre, pp. 14 a 32, especialmente pp. 17 e 18) que em algumas nações, como o México e Peru, o contingente indigenista é de alta significação. O que já não ocorre no Brasil e Argentina, de tradição luso-hispano-romana, no campo do Direito" salientando que não existe um único sistema, mas sistemas de caráter regional. Andrés Bello, por exemplo, para a elaboração do Projeto do Código chileno, de 1855, socorreu-se muito da Lei das Sete Partidas espanholas e do Código napoleônico; Teixeira de Freitas, no Brasil, para a realização de seu Esboço de Código Civil, de 1860, serviu-se das Ordenações Filipinas, de 1603, de Portugal, repudiando o Código Civil francês, em uma época na qual era moda esse Código de 1804, com numerosas nações seguindo sua trilha, copiando seus preceitos e imitando seu método extravagante. Também destaca o Código Civil boliviano, que se baseia, integralmente, no Código napoleônico; e o Código Civil argentino, oriundo do Projeto Vélez Sarsfield, que se vincula ao de Teixeira de Freitas, com suas origens claras, portanto.

Entretanto, reafirme-se, o romanismo está presente em todas essas codificações.

Existe verdadeira tradição-experiência romanística, pondera Sandro Schipani (Diritto Romano, Codificazioni e Unificazione del Diritto, in Revista de Direito Civil, Imobiliário, Agrário e Empresarial, Ed. Revista dos Tribunais, São Paulo, outubro/dezembro de 1980, n. 14, pp. 15 a 29, especialmente p. 28), que é "matriz de unificação, capaz de fornecer os instrumentos de um direito comum a quantos oferece a condição de cidadão 'soberano' entre cidadãos 'soberanos' $e$ iguais, condição fundada sobre própria e alheia atribuição ao 'populus'; capaz de renovar constantemente, por tal radicação, a crítica interna à realização $e$ 
estabilização de complexos de experiência jurídica que se demonstram inadequados, sobre a base da ação das forças culturais e sociais que não vêem completamente satisfeita tal condição e lutem por ela."

Acrescente-se que, no Brasil, nosso trabalho de codificação, desenvolvido, inicialmente, por Teixeira de Freitas e, depois, principalmente, por Coelho Rodrigues e por Clóvis Bevilaqua, está gravado do mais puro Direito Romano, que tende a manter-se como base do Direito Privado brasileiro.

Sim, porque os projetos do novo Código Civil brasileiro têm seguido, quase que integralmente, essa mesma orientação. Assim aconteceu com o Projeto de 1965, fundado no Anteprojeto apresentado por Orlando Gomes e com o Anteprojeto de 1972, que se converteu no Projeto de Lei n. 634 em 1975, n. 634-B, depois de aprovada sua redação pela Câmara dos Deputados, em 1984, ingressando no Senado da República sob n. 118, onde recebeu redação final em 1997.

A Comissão elaboradora e revisora desse último Anteprojeto, de 1972, foi composta por professores com sólida formação romanística, destacando-se dois romanistas, seus integrantes, José Carlos Moreira Alves e Ebert Vianna Chamoun.

Nossos manuais de Direito Privado mencionam, a cada passo, fundamentação no Direito Romano, para melhor entendimento do Direito atual.

\section{Ensino do Direito Romano no Brasil}

Diante do panorama brasileiro, até este ponto traçado, não tenho dúvidas de que a tendência é a de permanecer o sistema romanístico em nossa legislação, sendo, entretanto, necessário fortalecer o ensino do Direito Romano.

Como os brasileiros interessados no estudo do Direito tinham de estudar na Universidade de Coimbra, em Portugal, fundada em $1^{\circ}$ de março de 1290 , por diploma do rei D. Dinis, cristalizou-se o propósito da criação dos Cursos Jurídicos no Brasil, em 1822, logo após a conquista de sua Independência.

A primeira iniciativa, não-concretizada, de criação de um Curso de Direito, no Brasil, na Cidade do Rio de Janeiro, ocorreu pelo Decreto Imperial, de 9 de janeiro de 1825, tendo sido nesse mesmo ano elaborados seus estatutos, pelo Visconde de Cachoeira, Luís José de Carvalho e Melo, em que constava, entre as matérias do programa, as "Institutas do Direito Romano"

Dá-nos conta José Carlos Moreira Alves (Panorama da Literatura Romanística no Brasil, in Arquivos do Ministério da Justiça, Brasília, n. 164, 
outubro a dezembro de 1982, pp. 15 a 40, especialmente pp. 15 e 16; Aspectos do Ensino do Direito Romano na Faculdade de Direito de São Paulo, durante o Império, in Revista da Faculdade de Direito da Universidade de São Paulo USP, 1991, v. 86, pp. 9 a 43) que, em 1826, "Teixeira de Gouveia, na sessão de 12 de maio, propôs à Câmara dos Deputados que sua Comissão de Instrução Pública, revendo os trabalhos da Assembléia Constituinte, de 1823, trouxesse à consideração dos deputados projeto que ali fora discutido e aprovado, e cujo objeto era a criação de uma Universidade no Brasil. Na discussão dessa proposta, evoluiu-se para solução mais modesta: a criação, de imediato, de dois cursos jurídicos"

O imperador D. Pedro I, então, pelo Decreto Imperial de 11 de agosto de 1827. criou os dois primeiros cursos de Ciências Jurídicas e Sociais, um na cidade de São Paulo, no Estado de São Paulo, e outro na cidade de Olinda, no Estado de Pernambuco.

No currículo desses cursos não fez parte o Direito Romano, embora muita discussão tenha havido em torno de sua inclusão.

Esclarece Moreira Alves (Aspectos do Ensino do Direito Romano ..., p. 14) que durante 26 anos - de 1828 a 1854 os dois cursos jurídicos existentes no Brasil funcionaram sem a cadeira de Direito Romano. Sua necessidade, porém, até para o estudo mais completo de nosso Direito Civil, acabou por impor sua admissão no currículo. O Decreto Legislativo de 16 de agosto de 1851 incluiu, no segundo ano, a cadeira Institutas de Direito Romano, a qual só foi instalada três anos mais tarde, em 1854. Em São Paulo, essa instalação se deu em setembro desse ano. Já estavam em vigor, em substituição aos do Visconde da Cachoeira, os Estatutos dos Cursos Jurídicos mandados observar pelo Decreto n. 1.386, de 28 de abril de 1854 . Por eles (art. $1^{\circ}$ ), 'os atuais cursos jurídicos serão constituídos em Faculdades de Direito; designando-se cada uma pelo nome da Cidade, em que tem, ou possa ter assento: No ano seguinte, era aprovado pelo Decreto n. 1.568, de 24 de fevereiro, $o$ Regulamento Complementar dos Estatutos das Faculdades de Direito, expedido na conformidade do $\$ 3^{\circ}$ do art. 21 do citado Decreto n. 1.386."

Pelo aludido Decreto n. 1.386, de 1854, a matéria Institutas de Direito Romano começou a ser lecionada no primeiro ano do curso.

O Decreto n. 1.232-H, de 2 de janeiro de 1891, que introduziu a Reforma Benjamin Constant, passou a mesma disciplina para o segundo ano, com 0 título de Direito Romano. 
Informam-nos Agerson Tabosa e Maria Vital da Rocha (O Ensino do Direito Romano no Brasil, in Revista da Faculdade de Direito, Fortaleza, Ceará, janeiro a junho de 1990, v. 31, pp. 111 a 127), também escudados em informações de Moreira Alves, que mais três alterações do currículo jurídico ocorreram, no início da República, provocando o deslocamento da matéria de uma série para outra do curso de bacharelado, sendo certo que o Decreto n. 2.226, de 1896, a recolocou na primeira série. Com a Reforma Rivadávia Correia, passou-se a lecionar Direito Romano no terceiro ano do curso e, logo depois, com a Reforma Carlos Maximiliano, em 1915, voltou a integrar o elenco das disciplinas do primeiro ano.

Veio, então, a Reforma Francisco Campos, em razão do Decreto n. 19.852, de 11 de abril de 1931, que, ao lado do curso de bacharelado, criou o curso de doutorado, passando o Direito Romano a integrar as disciplinas deste último.

Com a Lei n. 114, de 11 de novembro de 1935, o Direito Romano voltou a ser ministrado no primeiro ano do curso de bacharelado.

Em 20 de dezembro de 1961, a Lei n. 4.024, conhecida como Lei de Diretrizes e Bases da Educação Nacional, outorgou competência ao Conselho Federal de Educação (CFE) para fixar os currículos mínimos dos cursos universitários, bem como da sua duração.

O presidente do Conselho Federal de Educação, com fundamento no Parecer n. 162-72, homologado pelo ministro da Educação e da Cultura, baixou, em 25 de fevereiro de 1972, a Resolução n. 3, fixando o currículo mínimo do curso de Direito, a ser obedecido a partir de 1973, não-incluindo o Direito Romano entre as disciplinas obrigatórias (básicas ou profissionais), deixando a critério das entidades de ensino superior sua inclusão ou-não, como disciplina obrigatória ou facultativa.

Editou-se, em 1994, a Medida Provisória n. 661, de 18 de outubro, que extinguiu o Conselho Federal de Educação (CFE), criando o Conselho Nacional de Educação (CNE). Em seguida, veio a lume a Medida Provisória n. 765, de 16 de dezembro de 1994. Com fundamento no art. $4^{\circ}$ desta última, e pela Portaria n. 1.886, de 30 de dezembro desse mesmo ano, que teve início de vigência em $1^{\circ}$ de janeiro de 1997 (conforme seu art. 15), o ministro da Educação e do Desporto fixou novas diretrizes curriculares e o conteúdo mínimo dos cursos jurídicos. Relacionam-se, nessa Portaria, em seu art. $6^{\circ}$, as disciplinas fundamentais e as profissionalizantes, sem menção expressa ao Direito Romano, que continua à mercê da preferência ounão das Instituições de Ensino Superior. 
Isto porque o parágrafo único do art. $6^{\circ}$ da aludida Portaria estabelece que "as demais matérias e novos direitos serão incluídos nas disciplinas em que se desdobrar o currículo pleno de cada curso, de acordo com suas peculiaridades e com observância de interdisciplinariedade"

Em tabela divulgada pelo Ministério da Educação e do Desporto (SEEC/MEC), em 1994, existiam, à época, no Brasil, 175 instituições, que oferecem curso de Direito, distribuídas entre os Estados da Federação: a. na Região Norte: em Rondônia, três; no Acre, uma; no Amazonas, uma; em Roraima, uma; no Pará, três; no Amapá, duas; em Tocantins, uma; num total de doze; b. na Região Nordeste: no Maranhão, três; no Piauí, uma; no Ceará, três; no Rio Grande do Norte, três; na Paraíba, quatro; em Pernambuco, quatro; em Alagoas, duas; em Sergipe, duas; na Bahia, três; num total de 25; c. na Região Sudeste: em Minas Gerais, 22; no Espírito Santo, quatro; no Rio de Janeiro, vinte; em São Paulo, 38; num total de 84; d. na Região Sul: no Paraná, doze; em Santa Catarina, dez; no Rio Grande do Sul, quinze; num total de 37; e. na Região Centro-Oeste: em Mato Grosso do Sul, duas; em Mato Grosso, três; em Goiás, nove; no Distrito Federal, três; num total de dezessete.

Atualmente, esses números estão bem alterados, para mais, dependendo de nova pesquisa do Ministério da Educação e do Desporto.

Tenha-se presente, neste passo, que os primeiros professores de Direito Romano da Faculdade de Direito de São Paulo, entre 1854 a 1889, então Academia autônoma, foram os catedráticos João Crispiniano Soares, Manuel Antônio Duarte de Azevedo, Francisco Antonio Dutra Rodrigues e Américo Brasiliense de Almeida Melo. Foram professores substitutos: Carlos Leôncio Carvalho, João Teodoro Xavier de Matos, João Jacinto Gonçalves de Andrade (cônego Andrade), José Maria Correia de Sá e Benevides José Joaquim Almeida Reis.

Esclarecem Agerson Tabosa e Maria Vital da Rocha (op. cit., pp. 112 a 126) que realizaram pesquisa, por um questionário, distribuído a 150 cursos de Direito, então existentes, com resposta de 118 deles (ou seja, de $81 \%$ ), no encontro de juristas em Niterói, Estado do Rio de Janeiro, por iniciativa da Faculdade de Direito da Universidade Federal Fluminense, no início de setembro de 1988. Tudo em razão de pergunta formulada pelo professor Pierangelo Catalano, do Grupo di Ricerca Sulla Diffusione del Diritto Romano e da Associazione di Studi Sociali Latinoamericani (ASSLA), a professores de Direito Romano: o Direito Romano é hoje estudado nos cursos jurídicos brasileiros? 
Os resultados foram divulgados em Fortaleza, por ocasião do IV Colóquio Ítalo-Brasileiro de Direito Romano, realizado de 28 a 30 de agosto de 1989.

Alinham, assim, os mesmos informantes: a. 150 Instituições consultadas (pp. 113 a 116); b. 77 Instituições que mantiveram Direito Romano em seu currículo; c. 55 Instituições em que o Direito Romano é obrigatório; d. 21 Instituições em que o Direito Romano é facultativo.

IV Necessidade de pesquisa sobre os dados do ensino do Direito Romano na América Latina

Foi, para mim, muito difícil levantar o modo pelo qual o Direito Romano está sendo lecionado na América Latina. Existe falta de material relativamente a esse assunto específico.

Seria preciso que, neste Congresso e em outros, pudéssemos, seguindo o exemplo da pergunta levantada pelo professor Pierangelo Catalano, já citada, proceder à coleta de informações junto aos participantes, envolvendo, nesse trabalho, as embaixadas e consulados.

Além dos dados estatísticos, que nos escapam, como: a. consta a disciplina Direito Romano do currículo pleno do curso de graduação? b. sendo positiva a resposta, a disciplina Direito Romano é obrigatória ou facultativa? c. se facultativa, está sendo oferecida aos alunos? d. em que carga horária está sendo ministrada? e. em quantos períodos? f. quantos alunos, em média, cursam Direito Romano, por período? g. quantos professores lecionam a disciplina e quais seus nomes? h. a matrícula em Direito Romano tem pré-requisito? i. se tiver, qual é esse pré-requisito? j. Direito Romano consta do currículo de pós-graduação? k. sendo positiva a resposta, em qual deles: especialização, aperfeiçoamento, mestrado oü doutorado? (conforme Agerson Tabosa e Maria Vital da Rocha, op. cit., pp. 112 e 113).

Seria de acrescentar-se: 1. quais as obras, e seus autores, existentes sobre o ensino do Direito Romano em seu País? m. em que bibliotecas podem essas obras ser localizadas?

Refira-se, entretanto, neste passo, que, no México, dá-nos notícia Jaime del Arenal Fenochio (Historia de la enseñanza del Derecho Romano em Michoacán México, 1799 a 1910, in Index a la Memoria de Angel Enrique Lapieza Elli, Quaderni camerti di studi romanistici, Ed. Jovene, Napoli, 1986, v. 14, pp. 263 
a 281, especialmente pp. 263, 270, 276 e 277) que, atualmente, o ensino do Direito Romano ocupa um lugar nas instituições educacionais mexicanas; todavia, em algumas épocas desapareceu, embora parece que, em outras, recobrou sua força, antes perdida.

Esse jurista mexicano mostra, com riqueza de pormenores, o desenvolvimento do ensino do Direito Romano, no Estado de Michoacán, desde 1799, que foi suprimido pela junta de professores do Colégio, em sessão de 1880.

Com altos e baixos, a disciplina foi e não-foi considerada, no aludido periodo, como retratado nessa excelente pesquisa.

Conclui esse mesmo autor que considera que o ensino do Direito Romano, no Estado Mexicano de Michoacán, "não contou com o suficiente apoio intelectual nem com o ambiente propício, desde seu início, para conseguir uma sólida formação romanista nos advogados michoacanos"

E assenta que a tragédia final sofrida pelo ensino jurídico romanista em Michoacán, no período analisado, resta claramente explicada quando entendemos os objetivos que chegaram a buscar com o estudo do Direito, em geral, no Seminário e na Escola de Jurisprudência do Estado, durante a luta fraticida que ensangüentou nosso país em princípios do século $X X^{\prime \prime}$ Acrescenta que o diretor da Escola, D. Miguel Mesa, em 1910, chegou a dizer que eram necessários "advogados de trabalho, homens úteis para magistrados, juízes, secretários e postulantes" bem preparados, para serem, mais tarde, legisladores e diretores da sociedade.

Ressalte-se, neste ponto, entretanto, segundo nos informa Mercedes Gyosso y Navarrete (Actividades del "Seminario de Derecho Romano" de la Facultad de Derecho de la Universidad Veracruzana, México, in Index c., p. 339), que a cátedra de Direito Romano foi reimplantada na Faculdade de Direito da Universidade Veracruzana, em 10 de outubro de 1980.

No Peru, conforme pondera Fernando de Trazegnies Granda (La evolución de los estudios de Derecho Romano en la Universidad Católica del Peru, in Index c., pp. 346 a 349), " o curso de Direito Romano era tradicional no currículo das Faculdades de Direito peruanas. Em geral, tratava-se de um curso obrigatório de primeiro ano, que, em algumas ocasiões, estava enquadrado em periodos anuais" Utilizava-se, como texto, o Manual de Direito Romano, de Eugène Petit, e, excepcionalmente, o Curso de Jörs, revisado por Künkel.

Informa, ainda, Fernando Granda que, nos anos 60, "o curso havia se convertido em algo muito elementar, sem professores verdadeiramente especialistas 
na matéria e com alunos que o seguiam com fastídio, unicamente porque tinha caráter obrigatório"

Nos anos 70, houve reforma radical do ensino, em que se enfatizou a perspectiva teórica e crítica, a fim de forçar a contribuição para a formação profissional e teórica, antes frustrada, segundo entendimento dos reformistas.

E conclui esse autor: "podemos dizer que o interesse atual pelo Direito Romano centra-se nos seguintes aspectos: a. uma preocupação teórica, enquanto o Direito Romano mostra um método de reflexão jurídica que pode servir de modelo ao nosso Direito atual; $b$. uma preocupação crítica, na medida em que $o$ Direito Romano pode apresentar elementos que talvez não tenham sido retomados por desenvolvimentos posteriores da tradição ocidental, mas que podem servir de base para a crítica do Direito atual ou de base para a reflexão a descobrir soluções aos problemas atuais (os 'futuristas'); c. uma preocupação sociológica, entendendose o Direito Romano como um exemplo da criação e adaptação de instituições jurídicas, em função de uma realidade histórica e social oscilante; d. uma preocupação histórica e arqueológica alheia a todo intento de aplicação moderna, para conhecer tal como foi, o que constitui parte do passado jurídico ocidental; e. uma preocupação histórica mais particularizada, na medida em que o Direito peruano (tanto durante o periodo espanhol quanto posteriormente) utilizou materiais de construção de origem romana"

Em Quito, no Equador, existiam, no século XVIII, duas universidades, informa Alberto Wray Espinosa (El estudio del Derecho Romano en la Universidad quiteña del siglo XVIII, in Ruptura, Revista Anual de la Asociación Escuela de Derecho, da Pontificia Universidad Catolica del Ecuador, Quito, 1988, n. 32, pp. 85 a 91), a de San Gregorio Magno, fundada pelos jesuítas em 1620 e extinta com a expulsão destes em agosto de 1776; e a de Santo Tomás de Aquino, fundada em 1688, pelos dominicanos.

Antes, existiu a Universidad de San Fulgencio, de 1586, de curta existência e que não-chegou a ter estudos de jurisprudência. Estes tiveram início, oficialmente, em Quito, no ano de 1693. Nesse ano, na Universidad de Santo Tomás, criaram-se as cátedras de Jurisprudência Civil e Cânones, juntamente com Medicina. Na Universidade de San Gregorio, as cátedras de Cânones e Leis foram criadas em novembro de 1704 . 
Nas duas universidades, os programas acadêmicos tinham como fundamento os Cursos de Leis e de "Institutạ" e ainda de Cânones. As Instituições de Direito Romano serviam para a análise da legislação positiva.

O texto oficial utilizado até 1791 foi o do holandês Arnold Vinnio (1588-1657), intitulada 'In quatuor libros institutionum imperialum commentarius" Essa obra compreende o texto das Institutas de Justiniano, completada com referências ao Digesto, notas e comentários.

Informa, ainda, Wray Espinosa que, em 1787, a Universidad de Santo Tomás foi secularizada, com uma nova Constituição, transformando-se na única universidade quitenha.

Esses novos estatutos de ensino jurídico estabeleceram: " $o$ Catedrático de Primeiras Leis, além de sua matéria atribuída, explique, como Fundamentos, qual seja em nosso Reino a autoridade do Direito Civil Romano...

Em 1791, a pedido do presidente da Audiência, o bispo de Quito, José Pérez Calama, preparou um novo Plano de Estudos, em que introduziu algumas inovações, fundamentando-as, e em que questionava de "forma reiterada a utilidade dos estudos de Direito Romano...

O mesmo bispo reconheceu que certas noções de Direito Romano, particularmente objetivado desde os aspectos históricos, são necessárias, recomendando a substituição da mencionada obra de Vinnio, pela do jurista italiano Juan Vicente Gravina (1664-1718).

Essa orientação do bispo Pérez Calama consolidou-se, em Quito, somente no século XIX, caracterizando-se, todavia, pela diminuição da importância atribuída ao Direito Romano; mantendo-se este, entretanto, como paradigma de racionalidade e coerência.

Conclui, então, o último citado autor que o Direito Romano ficou convertido, assim, em referência histórica"

A seu turno, Manuel Romero Gross (El Instituto Ecuatoriano de Derecho Romano, in Revista Ruptura, c., 1989, n. 33, pp. 169 a 174) menciona que no Primeiro Congresso Ítalo-Ecuatoriano de Direito Romano, nos dias 24 e 25 de novembro de 1988, dentre as conclusões tomadas em consenso geral, entendeu-se que "o estudo do Direito Romano nas Universidades Equatorianas cumpre um papel formativo e crítico e, por isso, não pode ser reduzido a poucas noções elementares. Portanto, expressa-se grave preocupação pela redução dos cursos de Direito Romano nas Faculdades de Jurisprudência das Universidades deste país, 
particularmente da Universidade Central do Equador, que é a mais antiga deste Estado e que fora berço de uma tradição jurídica orientada e fortalecida no Direito Romano"

Por todas essas razões e pelas fortes tradições de seus países, não podem, principalmente, os romanistas da América Latina deixar de lutar pela manutenção do Direito Romano, como disciplina obrigatória em seus currículos jurídicos. Com isso, estará assegurada a qualidade do ensino do Direito, também na América-Latina.

São Paulo, agosto de 1996. 